\title{
Male neonatal death and progressive weakness and immune deficiency in females: an unknown $\mathrm{X}$ linked condition
}

\author{
Geoffrey Woods, Graham Black, Gail Norbury
}

\begin{abstract}
We report a family with an undiagnosed $X$ linked condition. The grandmother, two of her three daughters, and one of her granddaughters have a slowly progressive proximal weakness, brisk reflexes, poor bladder function, static reduced night vision, and IgG2 deficiency. The diagnosis of the three living symptomatic females was "hereditary spastic paraplegia plus". They have lost five male children who died in the neonatal period of severe hypotonia and were of low birth weight. Investigations have not led to a unifying diagnosis: myotonic dystrophy, NARP, and $X$ linked hyper IgM were specifically eliminated. Using the hypothesis that the condition is $\mathbf{X}$ linked dominant, haplotype analysis of the family suggests that the disease locus is within Xq26-qter. This entity should be considered in the differential diagnosis of families presenting with severe neonatal hypotonia in males and females with symptoms suggestive of complex hereditary spastic paraplegia.
\end{abstract}

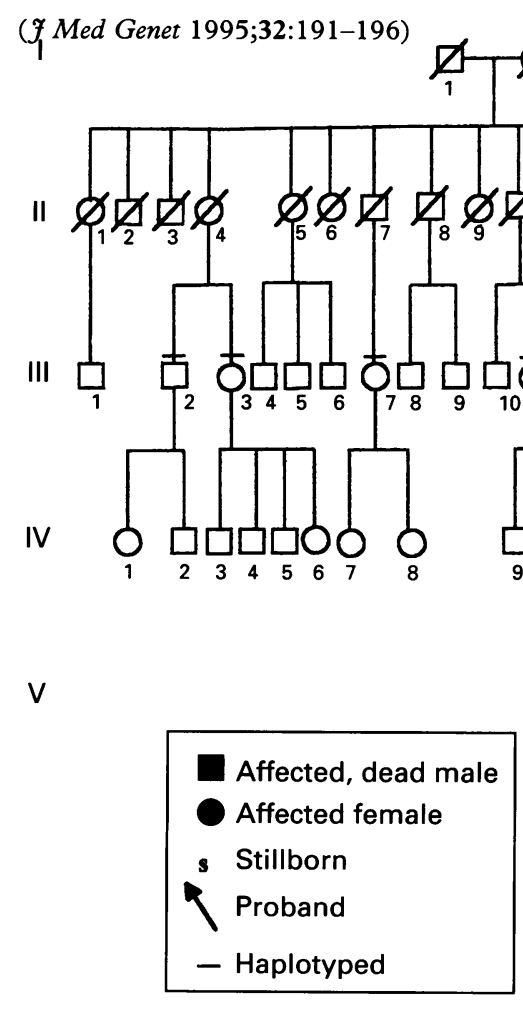

Department of Clinical Genetics, Churchill Hospital, Headington, Oxford, UK, and The Murdoch Institute, Royal Children's Hospital, Flemington Road, Parkville, Melbourne, Australia

C G Wood

Department of Genetics, University of Oxford, South Parks Road, Oxford, UK

G Black

Regional DNA Laboratory, Churchill Hospital, Headington, Oxford, UK

G Norbury

Correspondence to Dr Woods, The Murdoch Institute, Royal Children's Hospital, Flemington Road, Parkville 3052, Melbourne, Victoria, Australia.

Received 21 April 1994 Revised version accepted for publication 29 September 1994
It is unusual for both males and females to be consistently significantly symptomatic in an $\mathrm{X}$ linked disorder. We report such a family in which the affected males were severely hypotonic and died in the neonatal period and the affected females have a "complex hereditary spastic paraplegia".

Hereditary spastic paraplegia is a clinical diagnosis. Affected persons are spastic with little weakness. Pure forms of the condition are described, as are complex (plus) forms with additional features such as cerebellar ataxia, optic atrophy, deafness, and mental retardation. Most families exhibit either autosomal dominant or recessive inheritance; $\mathrm{X}$ linked hereditary spastic paraplegia is less common. The family described here is unusual because females are consistently affected and have the additional features of defective night vision and immune deficiency which are rarely described in hereditary spastic paraplegia. ${ }^{1}$ The condition appears to be distinct when compared to other $\mathrm{X}$ linked complex hereditary spastic paraplegias such as MASA (mental retardation, adducted thumbs, shuffling gait, aphasia), Allan-Herndon syndrome (spastic paraplegia, mental retardation, and muscle 
hypoplasia), and the family described by Kenwrick et al with mental retardation and optic atrophy. ${ }^{2-4}$

\section{Subjects and methods \\ CLINICAL DETAILS}

The pedigree is shown in fig 1 . The index case, IV $\cdot 31$, was referred after the unsuccessful resuscitation of her son, $\mathrm{V} \cdot 2$, at birth. Her mother III·19 and aunt III 15 had also lost male children in the neonatal period. All three women, and the maternal grandmother, II $\cdot 13$, had a "hereditary spastic paraplegia" with brisk deep tendon reflexes, slowly progressive weakness, poor bladder control, static poor night vision, and late onset immune deficiency. The maternal grandmother, II $\cdot 13$, was the last born of a sibship of 13. The condition has only occurred in her and her descendants.

Subjects III. 19 and IV·31 were investigated in depth. Other family members were interviewed and blood samples obtained from III. $2,3,7,11,12,13,14,15,16,17,18$, and IV 23 and 25 .

The clinical features of the four affected females were very similar. All had been ungainly as children and had been poor at sports in their youth. By the age of 30 they were noticeably unsteady on their feet and had frequent falls. Because of weakness II 13 , III $\cdot 15$, and III 19 needed to use wheelchairs by their fifth decade. All had static poor night vision, first noted in the first decade, having great difficulty walking, reading, or driving at night. Acuity and colour vision were normal. All complained of a weak bladder with giggle and stress incontinence. This had been noticed in the first decade but had not progressed. All had an increased number of sinopulmonary infections starting in the third or fourth decade. III 19 had suffered three pneumothoraces, the last leading to a pleurodesis. Bilateral cataracts were removed from II.13 at the age of 70 years and III.19 at 51 years. II 13 died of a coronary thrombosis at the age of 75 years.

II $\cdot 13$ was examined at the age of 67 years, III. 19 at 30 and 51 years, and IV.31 at 8,18 , and 27 years. All had lateral nystagmus. III 19 and IV.31 had mild facial and neck weakness. Their limb appearance was normal but by the second decade tone was increased in the legs but not the arms, power was reduced proximally in the legs, much more so than the arms, and hyperreflexia was found in the legs but not the arms. Upward plantar responses, slightly reduced proprioception, and pes cavus were present but peripheral coordination was normal. Knee and ankle clonus was elicited after the second decade. There were no abnormal peripheral cerebellar signs, myotonia, or contractures. When testable Romberg's sign was positive. Intellect and speech were normal in all four affected females. III 15 has not been examined.

III. 15 had four pregnancies and all were males. Her third born child is now a healthy 22 year old. The other three males died within four hours of birth, were hypotonic, and unable to maintain respiration. The first pregnancy was complicated by pre-eclamptic toxaemia and polyhydramnios. Labour was induced at 38 weeks of gestation. The second pregnancy ended at 5 months with premature labour and a stillborn male child. The fourth pregnancy went to term.

III 19 had three pregnancies. Female IV 31 was her first child and she herself had a daughter by her first pregnancy, who is 6 years old and well. The second and third pregnancies of III 19 and the second pregnancy of IV 31 were complicated by polyhydramnios in the last two months, but fetal movements were reported to be normal. Deliveries occurred at term of males weighing $2500 \mathrm{~g}, 2700 \mathrm{~g}$, and $2460 \mathrm{~g}$ who died within the first six hours.

\section{CLINICAL INVESTIGATIONS}

At necropsy V 2 had hypoplastic lungs (the left weighing $12 \mathrm{~g}$ and the right $15 \cdot 2 \mathrm{~g}$ ), a large left tension pneumothorax, bilateral talipes equinovarus, and a contracture of the right hand. All internal organs were normal including the brain. The dead males were of normal appearance but smaller than expected for their gestational age $(<3$ rd centile).

Detailed cytogenetic analyses of blood from III $\cdot 15$, III 19 , IV 31 , and V·2 were normal. Creatinine kinase of III $\cdot 15$, III $\cdot 19$, and IV 31 was normal. A lipid profile, thyroid function and antibodies tests, serum phytanic acid, and very long chain fatty acids levels were normal in III. 19 and IV.31.

A brain CT scan of III. 19 at the age of 52 years was normal, and in particular there were no features of multiple sclerosis. At the age of 31 years, IV.31 had neurophysiological examinations performed. The nerve conduction velocities of the right and left posterior tibial nerve and right ulnar nerve showed no significant abnormalities. The findings on EMG were consistent with a chronic neurogenic lesion and did not support the diagnosis of a myopathy. Muscle biopsy of the left biceps of IV.31 was reported as showing "some nonspecific changes which may represent those of a mild myopathy. Muscle fibres range in size from 55-62 $\mu \mathrm{m}$ with scattered atrophic fibres of types 1 and 2 . No central nuclei, inclusions, or nemaline bodies. Connective tissue was not increased and there was no inflammation. A trichrome stain showed a few prominent mitochondria in a few fibres".

Immune studies showed that III $\cdot 15$, III $\cdot 19$, and IV.31 all had IgG2 subclass deficiencies $(1 \cdot 0 \mathrm{~g} / \mathrm{l},<0 \cdot 08 \mathrm{~g} / \mathrm{l},<0 \cdot 4 \mathrm{~g} / 1$ respectively, the normal range being $1 \cdot 2-6 \cdot 6 \mathrm{~g} / \mathrm{l})$. All had low antibodies titres to diphtheria, Candida, and Pneumococcus. Levels of IgA, IgM, total IgG, IgG1, IgG3, and IgG4 were normal. Immunological studies of III 16 and III 17 (male and female sibs of the affected females III $\cdot 15$ and III·19) were normal. III·19 and IV.31 are successfully treated with three weekly gammaglobulin injections.

Ophthalmic assessment of IV 31 by slit lamp and shine through camera showed normal fundi and lens. In III-19 remnants of non-posterior pole cataracts were seen in both lenses. Neither 
Table 1 Markers used in the haplotype investigation

\begin{tabular}{lllll}
\hline Locus & Type & Localisation & $\begin{array}{l}\text { Annealing } \\
\text { temperature }\end{array}$ & Reference \\
\hline DMD 5' & (AC)n & Xp21 & $55^{\circ} \mathrm{C}$ & 7 \\
DXS228 & (AC)n & Xp11.4 & $53^{\circ} \mathrm{C}$ & 8 \\
DXS255 & VNTR & Xp11.22 & $65^{\circ} \mathrm{C}$ & 9 \\
HUMARA & (CAG)n & Xq11 & $5^{\circ} \mathrm{C}$ & 11 \\
DXS456 & (AC)n & Xq21-Xq22 & $55^{\circ} \mathrm{C}$ & 11 \\
DXS424 & (AC)n & Xq24-Xq26 & $55^{\circ} \mathrm{C}$ & 12 \\
XHM & (AC)n & Xq26 & $55^{\circ} \mathrm{C}$ & 13 \\
HPRT & (AGAT)n & Xq26 & $60^{\circ} \mathrm{C}$ & 14 \\
FRAXAC2 & (AC)n & Xq27.3 & $55^{\circ} \mathrm{C}$ & 15 \\
F8C & (AC)n & Xq28 & $53^{\circ} \mathrm{C}$ & 17 \\
DXS52 & VNTR & Xq28 & & 18 \\
CKMM & VNTR & $19 q 13.3$ & & Korneluk, see below \\
ApoC2 & (AC)n & $19 q 13.2$ & $55^{\circ} \mathrm{C}$ & \\
PH1100 & VNTR & $19 q 13.2$ & &
\end{tabular}

$\mathrm{PH} 1000$ is an unpublished marker also known as pKH1.1 and is located $200 \mathrm{~kb}$ centromeric of the myotonic dystrophy gene, between it and ERCC1 (R Korneluk, personal communication).

had any findings suggestive of myotonic dystrophy. Electroretinograms were reported as showing "slight reduction of amplitude in photopic conditions, normal in scotopic" in both. Dark adaptation studies in III-19 showed an absent alpha point (break between rod and cone function) in the right eye and a normal result in the left; in IV.31 a bilaterally absent alpha point was found. These results are not typical of "stationary night blindness", but may represent a defect of rod/cone interaction. The significance of these results is unclear as is the cause of the reduced night vision.

PREPARATION OF GENOMIC DNA

DNA from peripheral blood was extracted by standard procedures. ${ }^{5}$

\section{AMPLIFICATION OF SATELLITE REPEATS}

PCR was carried out in $20 \mathrm{ml}$ reaction volumes overlaid with paraffin oil. The reaction mix consisted of 100 to $200 \mathrm{ng}$ of genomic DNA, $0.5 \mathrm{mmol} / 1$ of each primer, $2 \mathrm{ml}$ of Perkin Elmer Cetus $10 \times$ concentration reaction buffer, $0.2 \mathrm{mmol} / 1$ each of dGTP, dATP, dCTP, and dTTP, and $0.1 \mathrm{ml} \mathrm{Taq}$ polymerase (Perkin Elmer Cetus). Before amplification $50 \%$ of one primer was end labelled with $\mathrm{T} 4$ polynucleotide kinase (Boehringer Mannheim), and [ $\left.{ }^{32} \mathrm{P}\right]$ ATP using standard procedures. ${ }^{6}$ Samples were processed through 35 cycles of denaturation $\left(94^{\circ} \mathrm{C}\right.$ for 45 seconds), annealing (see table 1 for temperatures for 45 seconds), and elongation $\left(72^{\circ} \mathrm{C}\right.$ for one minute). For analysis, PCR prod- ucts were run on $6 \%(\mathrm{w} / \mathrm{v})$ polyacrylamide, $11 \%$ urea denaturing gels. For details of PCR probes, see table 1 .

\section{RFLP ANALYSIS}

DNA samples were digested overnight with the appropriate restriction endonuclease $(E c o R I$ at $37^{\circ} \mathrm{C}$ for DXS255, PH1100, and GB2.2; TaqI at $65^{\circ} \mathrm{C}$ for DXS52 and CKMM; and NcoI at $37^{\circ} \mathrm{C}$ for CKMM) and analysed by Southern blot hybridisation using probes labelled by random priming ("Multiprime", Amersham Biochemicals)

To assess $\mathrm{X}$ inactivation, probe DXS255 at Xp11.22 was used. ${ }^{19}$ DNA samples were digested with PstI, ethanol precipitated, and digested with $M s p$ I or HpaII (all enzymes from Boehringer Biochemicals).

\section{NARP MUTATION DETECTION}

The NARP mutation present at position 8993 in the ATPase subunit 6 of the mitochondrial genome was sought using polymerase chain reaction amplification followed by AvaI restriction. $^{20}$

\section{$X$ LINKED HYPER IGM IMMUNODEFICIENCY (XHM)}

The gene for $\mathrm{X}$ linked hyper IgM (XHM) has recently been cloned and the cDNA sequence published. ${ }^{12}$ A polymorphic microsatelite (AC) $n$ repeat in the $5^{\prime}$ untranslated region of the gene was amplified by polymerase chain reaction and used for both haplotype analysis and to attempt deletion detection.

\section{MYOTONIC DYSTROPHY MUTATION EXPANSION} DETECTION

The (CTG) expansion associated with myotonic dystrophy was sought both with the probe GB2.2 (a PstI digest of probe GB2.6) digested with $E c o$ RI by Southern blotting and agarose gel, and by PCR of the expansion analysed both by ethidium bromide staining and radiolabelled (CTG) probe. $^{2122}$

\section{Results}

$X$ CHROMOSOME HAPLOTYPE ANALYSIS

Using the hypothesis that the family had an $\mathrm{X}$

Table 2 Haplotype results of family members

\begin{tabular}{|c|c|c|c|c|c|c|c|c|c|c|c|c|c|c|c|}
\hline Probe & $I I I \cdot 2$ & $I I I \cdot 3$ & $I I I \cdot 7$ & $I I I \cdot 11$ & $I I I \cdot 12$ & $I I I \cdot 13$ & $I I I \cdot 14$ & $I I I \cdot 15$ & $I I I \cdot 16$ & $I I I \cdot 17$ & $I I I \cdot 18$ & $I I I \cdot 19$ & $I V \cdot 23$ & $I V \cdot 25$ & $I V \cdot 31$ \\
\hline \multicolumn{16}{|l|}{$\mathrm{X}$ chromosome } \\
\hline DMD $5^{\prime}$ & B & $\mathrm{AB}$ & $\mathrm{CC}$ & BC & AC & AC & & AC & AB & $\mathrm{C}$ & C & $\mathrm{AC}$ & $\mathrm{C}$ & & $\mathrm{AC}$ \\
\hline 1 Aa6 & A & AC & AA & AC & $\mathrm{AA}$ & AA & A & $\mathrm{AB}$ & $\mathrm{AB}$ & A & A & AB & A & & $\mathrm{AB}$ \\
\hline DXS255 & B & DG & $\mathrm{BH}$ & EK & $\mathrm{AD}$ & $\mathrm{AE}$ & $\mathrm{E}$ & $\mathrm{BD}$ & $\mathrm{BB}$ & D & A & $\mathrm{BD}$ & D & & $\mathrm{AB}$ \\
\hline And $\operatorname{Rec}$ & $\mathrm{D}$ & & $\mathrm{AD}$ & EF & $\mathrm{BC}$ & $\overline{C E}$ & & $\mathrm{AB}$ & $\mathrm{AD}$ & B & C & $\mathrm{AB}$ & B & & $\mathrm{CC}$ \\
\hline DXS456 & A & $\mathrm{AB}$ & $\mathrm{CC}$ & AC & & & A & $\mathrm{AA}$ & $\mathrm{CC}$ & $\vec{A}$ & A & $\mathrm{AC}$ & $\mathrm{C}$ & & $\mathrm{AC}$ \\
\hline DXS424 & A & $\mathrm{AB}$ & AA & $\mathrm{AC}$ & AC & $\mathrm{AC}$ & A & $\mathrm{AD}$ & $\mathrm{AD}$ & A & A & $\mathrm{AD}$ & D & & $\mathrm{AD}$ \\
\hline XHM & C & AC & $\mathrm{CC}$ & $\mathrm{CC}$ & $\mathrm{CC}$ & CC & $\mathrm{C}$ & $\mathrm{BC}$ & BC & C & A & BC & B & & $\mathrm{AB}$ \\
\hline HPRT & A & BE & $\mathrm{BE}$ & CE & $\mathrm{BE}$ & $\mathrm{AB}$ & A & $\mathbf{A B}$ & $\mathrm{BE}$ & E & C & $\mathrm{AB}$ & B & & $\mathrm{BC}$ \\
\hline FRAXAC2 & A & BB & BB & $\mathrm{BB}$ & $\overline{B C}$ & $\mathrm{AC}$ & & $\mathrm{AC}$ & $\mathrm{BC}$ & B & B & $\mathrm{AC}$ & $\mathrm{C}$ & & $\mathrm{AB}$ \\
\hline DXS52 & A & $\mathrm{BD}$ & BD & $\mathrm{BC}$ & $\mathrm{CD}$ & $\mathrm{AD}$ & & $\mathrm{AB}$ & $\mathrm{BC}$ & $\mathrm{C}$ & B & $\mathrm{AB}$ & B & & $\mathrm{AB}$ \\
\hline F8C & C & $\mathrm{CG}$ & BC & $\mathrm{BF}$ & DF & $\mathrm{CD}$ & & $\mathrm{CD}$ & $\mathrm{DF}$ & $\mathrm{F}$ & $\mathbf{H}$ & $\mathrm{CD}$ & $\mathrm{D}$ & & $\mathrm{CH}$ \\
\hline \multicolumn{16}{|c|}{ Chromosome 19} \\
\hline ApoC2 & 13 & 13 & 34 & & 34 & & & 36 & & 23 & 36 & 36 & 67 & & 34 \\
\hline CKMM-Ta & 11 & 11 & 12 & & 11 & 11 & 12 & 12 & & 12 & 12 & 12 & 12 & 11 & 12 \\
\hline CKMM-Nc & $=22$ & 12 & 12 & & 22 & 22 & 22 & 22 & & 12 & 22 & 12 & 22 & 22 & 22 \\
\hline PH1100 & 12 & 12 & 12 & & 12 & 11 & 12 & 12 & & 11 & 12 & 12 & 11 & 12 & 12 \\
\hline
\end{tabular}




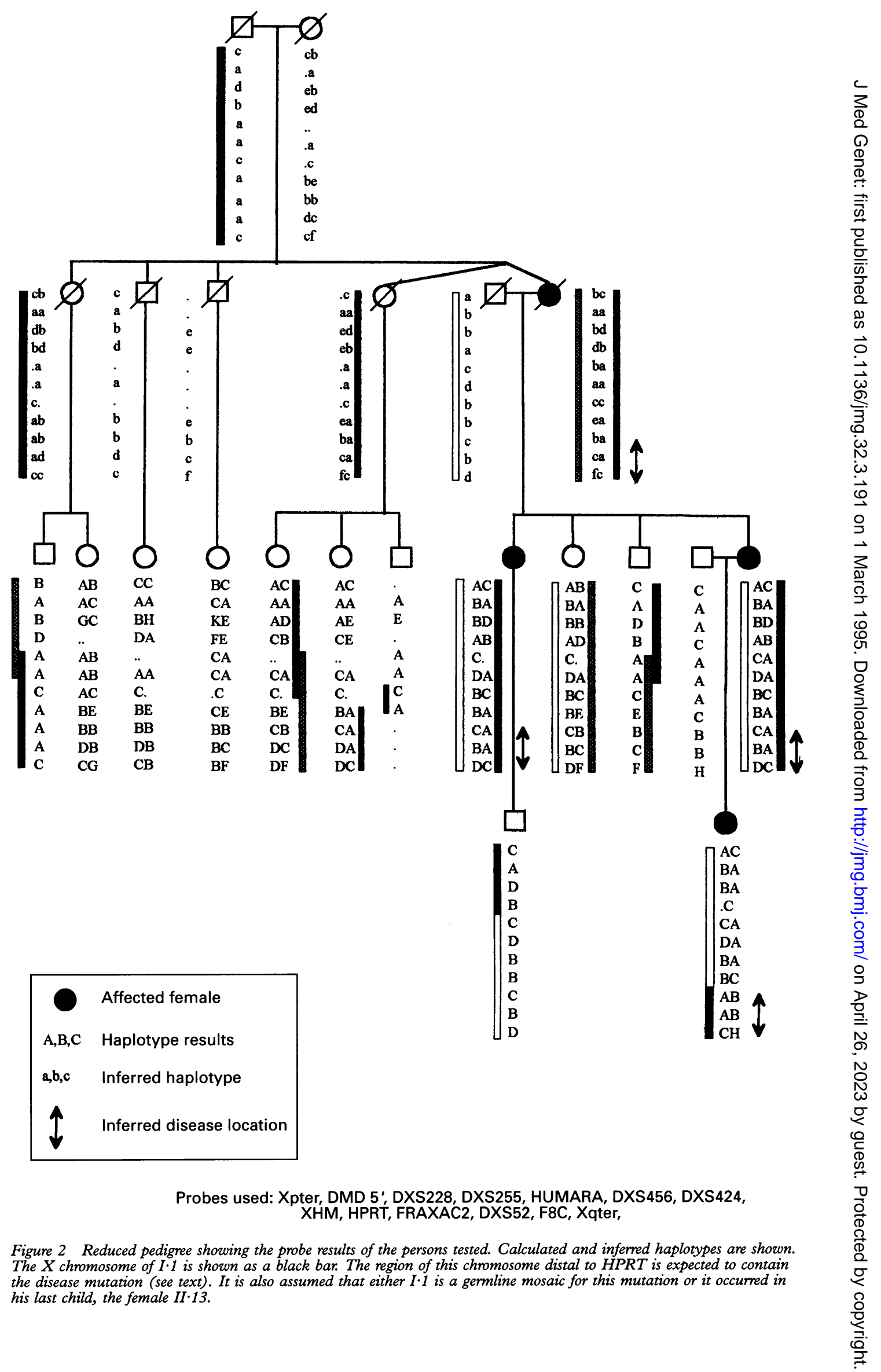

linked dominant condition, we performed X 20 years who have no neurological symptoms chromosome haplotype analysis. We have as- do not have the condition and that females sumed that living males and females aged over with neurological and immunological features 
do have the condition.

Using 11 markers spaced along the length of the $\mathrm{X}$ chromosome we analysed the segregation of the $\mathrm{X}$ chromosomes in this family. The results are set out in table 2 and shown in fig 2 . Within the nuclear family containing affected subjects (progeny of grandmother II·13), Xq26-Xqter is implicated as the region containing the disease associated mutation. The lod score for each marker is 1.5 at $\theta=0$ in this approximately 10-14 megabase segment of the $\mathrm{X}$ chromosome distal to the HPRT locus on $\mathrm{Xq} 26$.

Using all available family members, as shown in fig 2 , and making the assumption that the calculated haplotypes are correct, the region that we hypothesise to carry the disease mutation in the grandmother II 13 has been passed to III. 2 and III 13 , while that region on her other X chromosome has been passed to III 12 . All three and their offspring are well. The mutation bearing segment may have been derived from their grandfather, $I \cdot 1$, in which case he would have been a gonadal mosaic.

EXCLUSION OF DIFFERENTIAL DIAGNOSES: NARP (NEUROGENIC WEAKNESS, ATAXIA, RETINITIS PIGMENTOSA), X LINKED HYPER IGM IMMUNODEFICIENCY (XHM), AND MYOTONIC DYSTROPHY

Subjects III.19 and IV.31 did not have the NARP mutation. $X$ linked hyper IgM immunodeficiency maps close to the HPRT locus on $\mathrm{Xq} 26$, within the disease bearing region of Xq defined by haplotype analysis. ${ }^{23}$ If the locus were to be involved in this condition then it would probably be as part of a contiguous gene deletion. No deletion was detected in the affected females. Furthermore the locus segregates with HPRT, proximal to the recombination event in IV.31. On this basis, the $\mathrm{XHM}$ locus can be excluded as the origin of the immune deficiency in this family. We considered it important to exclude myotonic dystrophy as a possible diagnosis despite the detailed family clinical picture being unusual. Subjects III $\cdot 15$, III 19 , and IV 31 had a normal myotonic dystrophy triplet repeat size. Using an autosomal dominant model of inheritance we were unable to show linkage between the disease and the 19q13.3 haplotype in family members using the probes ApoC2, CKMM, and pH1000 (table 2).

\section{$\mathrm{X}$ INACTIVATION ANALYSIS}

The putative mutation bearing $\mathrm{X}$ chromosome was determined by haplotype analysis. Subjects III. 19 and IV.31 exhibited a skewed $X$ inactivation pattern, $80 \%$ and $90 \%$ of the unaffected haplotype respectively, as determined with DXS255. As all three females had a similar degree and spectrum of symptoms we conclude that either $\mathrm{X}$ inactivation is not a significant factor in the phenotype of this condition or that we were measuring $\mathrm{X}$ inactivation in the wrong tissue.

\section{Discussion}

In this family five male children have died with severe hypotonia in the neonatal period. Diminished fetal movement in utero is suggested by their low birth weights, polyhydramnios in later pregnancy, and contractures present at birth. Necropsy examination was incomplete but no structural anomalies of the nervous system were seen. Of the four females affected by the condition, two women have been investigated in detail. Pertinent findings are: progressive proximal weakness, brisk reflexes, normal touch and proprioception, an increased incidence of sinopulmonary infections, and non-progressive difficulties with night vision and bladder control. Investigations showed an unusual cone/ rod dark adaptation response and low IgG2. The original diagnosis made in the affected females of this family was hereditary spastic paraplegia.

This pattern of clinical features has not previously been reported. The family is too small to allow a definitive statement about the mode of inheritance. The best fit to the data is $\mathrm{X}$ linked dominant although $\mathrm{X}$ linked recessive and maternal/mitochondrial inheritance are also possible. We have attempted to define a group of diseases which represent the potential differential diagnoses as well as considering the possibility that the causative mutation is a deletion encompassing a number of genes and giving a compound phenotype.

The clinical features in our family are not typical of the several $\mathrm{X}$ linked conditions which cause night blindness, including retinitis pigmentosa, stationary night blindness (both of which show probable genetic heterogeneity), Aland eye disease, and deletions encompassing the chorioderaemia gene. As the IgG2 deficiency was associated with an increased number of sinopulmonary infections we considered it a significant finding. Although at least seven $\mathrm{X}$ linked immunodeficiency disorders exist, in none would the female carriers be consistently symptomatic. As X linked hyper IgM (XHM) causes similar immunological features we excluded this gene. Considering the conditions that can cause severe neonatal hypotonia, we excluded myotonic dystrophy by analysis of the triplet repeat mutation expansion. Although Barth syndrome (3-methylglutacaconic aciduria type 2) can cause severe male neonatal hypotonia and male neonatal death, the clinical picture seen in the affected females is atypical. ${ }^{2425}$ The family described by Zollino with an $\mathrm{X}$ linked dominant condition presenting in males with severe congenital hypotonia also seems distinct as the affected males were dysmorphic, hypogonadic, and had pachygyria. ${ }^{26}$ The $\mathrm{X}$ linked form of myotubular myopathy (centronuclear myopathy) can cause male neonatal death but seems an unlikely diagnosis as females are usually asymptomatic and are not described to have visual and immune deficiencies. ${ }^{27-30}$ Neurogenic weakness, ataxia, retinitis pigmentosa (NARP) was eliminated by direct mutation analysis.

By analysis of meiotic crossovers using an $\mathrm{X}$ linked dominant model the disease locus maps 
to the region $\mathrm{Xq} 26$ to Xqter. Linkage of pure hereditary spastic paraplegia has been to Xq2122 in one family, ${ }^{31}$ in a family with AllanHerndon to $\mathrm{Xq} 21,{ }^{3}$ in the family described by Kenwrick et $a l^{4}$ to $\mathrm{Xq} 28$, and in MASA syndrome to $\mathrm{Xq} 28 .{ }^{2}$ Given the possible localisation of the condition we describe to Xq2628 it may prove to be allelic to one of the latter two diseases. There was no evidence of skewed $\mathrm{X}$ inactivation in the blood of three obligate affected females, nor of an $\mathrm{X}$ chromosome deletion.

Two observations have previously been made which are pertinent to this report: (1) that Xqter seems to contain a disproportionate number of male lethal conditions, and (2) that families such as this may be unreported because of the small family size and difficulty in obtaining sufficient data. ${ }^{32}$

This disorder is important to consider in apparently $\mathrm{X}$ linked families where females present with progressive weakness or males with severe neonatal hypotonia or both. We suggest that this condition be known as Lindenbaum syndrome.

We would like to thank the following doctors involved in the care and investigation of this family: Miss B Billington, Dr A Boon, Professor Bron, Dr H Chappel, Dr D Hilton-Jones, Dr N Hymann, Dr J Oxbury, Dr W Squires, and Professor J H N Hymann, Dr J Oxbury, Dr W Squires, and Professor J Edwards. We would also like to acknowledge the essential
contribution to this paper of the late Dr Richard H Lindenbaum.

1 Harding AE. The hereditary ataxias and related disorders. London: Churchill Livingstone, 1984: 189-90.

2 Boyd E, Schwartz CE, Schroer RJ, May MM, Shapiro SD. Agenesis of the corpus callosum associated with the MASA syndrome. Clin Dysmorphol 1993;2:332-41.

3 Stevenson RE, Goodman HO, Schwartz CE, et al. AllanHerndon syndrome I. Clinical studies. Am $\mathcal{F}$ Hum Genet 1990;47:446-53.

4 Kenwrick S, Ionasescu G, Ionasescu D, et al. Linkage studies of $\mathrm{X}$ linked recessive spastic paraplegia using DNA probes. Hum Genet 1986;73:264-6.

5 Maniatis T, Fritsch EF, Sambrook J. Molecular cloning: a laboratory manual. New York: Cold Spring Harbor Laboratory Press, 1982.

6 Sanger F, Nicklen S, Coulsen AR. DNA sequencing with chain terminating inhibitors. Proc Natl Acad Sci USA 1977 74:5463-7.

7 Feener CA, Boyce FM, Kunkel LM. Rapid detection of CA polymorphisms in cloned DNA: application to the $5^{\prime}$ end of the dystrophin gene. Am f Hum Genet 1991;48:621-7.

8 Coleman M, Murray JC, Willard HF, et al. Genetic and physical mapping around the properdin P gene. Genomics 1991;11:991-6.

9 Fraser NJ, Boyd Y, Brownlee GG, Craig IW. Multi-allelic RFLP for M27b an anonymous single copy genomic clone at Xp11.3-Xcen (HGM9 provisional no DXS255). Nucleic Acids Res 1987;15:9616.

10 Allen RC, Zoghbi HY, Mosely AB, Rosenblatt HM, Belmont JW. Methylation of HpaII and HhaI sites near the polymorphic CAG repeat in the human androgen-receptor
gene correlates with $\mathrm{X}$ chromosome inactivation. $\mathrm{Am} \mathcal{f}$ gene correlates with X chrom

11 Luty JA, Guo Z, Willard HF, Ledbetter DH, Ledbetter S,
Litt $M$. Five polymorphic microsatellite VNTRs on the human X chromosome. Am $\mathcal{F}$ Hum Genet 1990;46:776-83. 12 Spriggs KS, Armitage RJ, Stockbine L, et al. Recombinant human CD40 ligand stimulates B cell proliferation and immunoglobulin E secretion. $\mathcal{F}$ Exp Med 1992;176:154350 .

13 Edwards A, Civitello A, Hammond HA, Caskey CT. DNA typing and genetic mapping with trimeric and tetrameric repeats. Am $\mathcal{F}$ Hum Genet 1991;49:746-56.

14 Richards RI, Holman K, Horzman $\mathrm{H}$, et al. Fragile X syndrome: genetic localisation by linkage mapping of two microsatellite repeats FRAXAC1 and FRAXAC2 which immediately flank the fragile site. $\mathcal{F}$ Med Genet 1991;28: 818-23.

15 Lalloz MRA, McVey JH, Pattinson JK, Tuttenham EGD. Haemophilia A diagnosed by analysis of a hypervariable dinucleotide repeat within the factor VIII region. Lancet 1991;338:207-11.

16 Feil R, Palmieri G, d'Urso M, Heilig R, Oberle I, Mandel JL. Physical and genetic mapping of polymorphic loci in Xq28 (DXS15, DXS52, and DXS134): analysis of a cosmid clone and a yeast artificial chromosome. $A m \mathcal{f}$ cosmid clone and a yeast

17 Perryman MB, Hejmancik JF, Ashizawa T, et al. Ncol and Taq1 RFLP's for human creatinine kinases (CKMM). Nucleic Acids Res 1988;16:8744.

18 Weber JL, May PE. Abundant class of human DNA polymorphisms which can be typed using the polymerase chain reaction. Am F Hum Genet 1989;44:388-96.

19 Hendriks RW, De Weers M, Mensink RGJ, et al. Diagnosis of Wiscott-Aldrich syndrome by analysis of $\mathrm{X}$-chromosome inactivation patterns in the maternal leucocyte populations using the hypervariable DXS255 locus. Clin Exp Immunol 1991;84:219-22.

20 Holt IJ, Harding AE, Petty RKH, Morgan-Hughes JA. A new mitochondrial disease associated with mitochondrial

21 Brooks JD, McCurrack ME, Harley HG, et al. Molecular basis of myotonic dystrophy expansion of a trinucleotide (CTG) repeat at the $3^{\prime}$ end of a transcript encoding a

22 Mahedevan M, Tsilfidis C, Sabourin L, et al. Myotonic dystrophy: an unstable CTG repeat in the 3-prime untranslated region of the gene. Science 1992;255:1253-5.

23 Padayachee M, Feighrey C, Finn A, et al. Mapping of the $\mathrm{X}$-linked form of hyper-IgM syndrome (HIGM1) to Xq26 by close linkage to HPRT. Genomics 1992;14:551-3.

24 Barth PG, Scholte JA, Berden JA, et al. An X-linked mitochondrial disease affecting cardiac muscle, skeletal and muscle and neutrophil leukocytes. $\mathcal{F}$ Neurol Sci 1983;62: 327-35.

25 Kelley RI, Cheatam JP, Clark BJ, et al. X-linked dilated cardiomyopathy with neutropenia, growth retardation and 3-methylglutaconic aciduria. of Pediatiatr 1991;119:73847.

26 Zollino M, Mastroiacovo P, Zampino G, Mariotti P, Neri G. New XLMR syndrome with characteristic face, hypogenitalism, congenital hypotonia and pachygyria. $A m \mathcal{F}$ genitalism, congenital hyp

27 Barth PG, Van Wijngaarden GK, Bethlem J. X-linked myotubular myopathy with fatal neonatal asphyxia. Neurology 1975;25:531-6.

28 Keppen LD, Husain MM, Woody RC. X-linked myotubular myopathy: intrafamilial variability and normal muscle biopsy in a heterozygote female. Clin Genet 1987;32:95-9.

29 Van Wijngaarden GK, Fleury P, Bethlem J, Hugo Meijer AEF. Familial "myotubular" myopathy. Neurology 1969; 19:901-8.

30 Thomas NST, Williams H, Cole G, et al. X-linked neonatal centronuclear/myotubular myopathy: evidence for linkage to Xq28 DNA marker loci. 7 Med Genet 1990;27:284-7.

31 Keppen LD, Leppert MF, O'Connell $\mathrm{P}$, et al. Etiological heterogeneity in X-linked spastic paraplegia. Am f Hum Genet 1987;41:933-43.

32 Bolhuis PA, Hensels GW, Hulsebos TJM, Baas F, Barth PG. Mapping of the locus for X-linked cardioskeletal PG. Mapping of the locus for X-linked cardioskeletal (Barth syndrome) to Xq28. Am $\mathcal{f}$ Hum Genet 1991;48: 481-5. 